\title{
Peran Subjective Well-Being dan Trust in The Employer terhadap Organizational Citizenship Behavior (OCB) Karyawan
}

\author{
Fatwa Tentama $^{1^{*}}$, Cita Yuliantin ${ }^{2}$ \\ Universitas Ahmad Dahlan Yogyakarta \\ ${ }^{1}$ fatwa.tentama@psy.uad.ac.id, ${ }^{2}$ citayuliantin@gmail.com \\ *Correspondence
}

\section{Article Information:}

Received 17 November 2020

Revised 04 October 2021

Accepted 05 October 2021

\section{Keywords:}

subjective well-being; trust in the employer; organizational citizenship behavior
Kata Kunci:

subjective well-being; trust in the employer; organizational citizenship behavior
Organizational citizenship behaviour is one of the behaviours that can affect the company's success, so it is necessary to study the factors that can influence it. This study examines the effect of subjective well-being and trust in the employer on employee organizational citizenship behaviour. The population in this study were 110 permanent employees at an automotive company in Yogyakarta. The research sample was 70 employees with the characteristics of working in an automotive company, a minimum of one year of service, a permanent employee who did not work in the workshop. The sample selection was male and female with a nonprobability purposive sampling technique. The research instrument used was organizational citizenship behaviour, subjective well-being, and trust in the employer scales. Hypothesis testing using multiple linear regression analysis with SPSS V.21 program. Simultaneous analysis results show a significant effect of subjective well-being and trust on employee organizational citizenship behaviour. The partial analysis shows a very significant positive effect of subjective well-being on organizational citizenship behaviour and trust in the employer on organizational citizenship behaviour. Subjective well-being and trust in the employer contributed $49 \%$ to organizational citizenship behaviour. The amount of contribution given by subjective well-being contribution is $20.66 \%$, and trust in the employer is $28.31 \%$. Thus trust in the employer provides a more dominant contribution to organizational citizenship behaviour.

Abstrak
Organizational citizenship behavior merupakan salah satu
perilaku vital yang dapat mempengaruhi keberhasilan
perusahaan sehingga perlu dikaji faktor-faktor yang dapat
mempengaruhinya. Penelitian ini bertujuan untuk menguji
pengaruh subjective well-being dan trust in the employer
terhadap organizational citizenship behavior karyawan. Populasi
dalam penelitian ini adalah 110 karyawan karyawan tetap di salah
satu perusahaan otomotif di Yogyakarta. Sampel penelitian
adalah 70 karyawan dengan kharakteristik bekerja di perusahaan
otomotif, masa kerja minimal satu tahun, berstatus sebagai
karyawan tetap, tidak bekerja di bagian bengkel dan berjenis
kelamin laki-laki dan perempuan. Pemilihan sampel dengan


nonprobability melalui teknik purposive sampling. Instrumen penelitian yang digunakan terdiri dari skala organizational citizenship behavior, subjective well-being, dan trust in the employer. Pengujian hipotesis menggunakan analisis regresi linear berganda dengan program SPSS V.21. Hasil analisis secara simultan menunjukkan ada pengaruh yang sangat signifikan subjective well-being dan trust in the employer terhadap organizational citizenship behavior karyawan. Hasil analisis secara parsial menunjukkan bahwa ada pengaruh positif yang sangat signifikan subjective well-being terhadap organizational citizenship behavior dan trust in the employer terhadap organizational citizenship behavior. Subjective well-being dan trust in the employer memberikan kontribusi terhadap organizational citizenship behavior sebesar 49\%. Besarnya kontribusi yang diberikan subjective well-being sebesar 20,66\% dan trust in the employer sebesar $28,31 \%$, dengan demikian trust in the employer memberikan kontribusi yang lebih dominan terhadap organizational citizenship behavior.

\section{PENDAHULUAN}

Pertumbungan industri otomotif di Indonesia sangatlah pesat dengan tingkat persaingan yang begitu tinggi. Fenomena yang terjadi di salah satu perusahaan otomotif di Yogyakarta menunjukkan bahwa banyak ditemui perilaku karyawan yang bekerja seadanya, pelanggaran terhadap aturan-aturan kerja, datang ke kantor terlambat, mengeluh dan tidak mau mentoleransi terhadap keadaan kerjanya, sulit terlibat aktif dalam tim kerja dan lebih suka bekerja individual. Perusahaan membutuhkan strategi untuk mengatasi permasalahan tersebut dan membutuhkan karyawan-karyawan yang mampu bekerja maksimal dan bahkan bekerja extra melebihi standar yang ditentukan. Perusahaan mendambakan karyawan dapat bekerja lebih extra dengan lebih taat dan patuh pada aturan kerja yang ditentukan, dapat bekerja maksimal dalam tim, saling membantu tugas rekan kerja yang membutuhkan, dapat datang ke kantor lebih awal, tidak membuang-buang waktu dalam bekerja, tidak terlalu banyak mengeluh dengan keadaan perusahaan saat ini ataupun membesar-besarkan masalah yang dapat menjelekkan nama perusahaan.

Dalam dunia kerja, istilah yang digunakan untuk menggambarkan kesediaan tersebut dikenal dengan organizational citizenship behavior. Organizational citizenship behavior telah menjadi salah satu tema yang paling banyak diteliti dalam kajian psikologi industri dan literatur manajemen sumber daya manusia (Brockner, Flynn, Dolan, Ostfield, Pace, \& Ziskin, 2006); (Ocampo, Acedillo, Bacunador, Balo, Joreen, \& Tupa, 2018). Konsep ini pertama kali didefinisikan oleh Organ (1988) sebagai sekumpulan perilaku individu yang secara sukarela berkontribusi pada berfungsinya perusahaan, terlepas dari sistem penghargaan formal.

Kesukarelaan merupakan esensi dari organizational citizenship behavior sehingga meskipun tidak direncanakan dalam sistem penghargaan perusahaan, karyawan bersedia berkontribusi lebih terhadap efektivitas kinerja perusahaan seperti 
melibatkan dirinya dalam beberapa penugasan tidak resmi yang diberikan perusahaan (Bamel, Rangnekar, Stokes, \& Rastogi, 2013); (Kataria, Garg \& Rastogi, 2012). Ketika karyawan suatu perusahaan memiliki dan menunjukkan organizational citizenship behavior, akan tembentuk iklim organisasi yang positif yang akan berimplikasi pada meningkatnya kesejahteraan karyawan dan rendahnya turnover intentions.

Lingkungan seperti ini memungkinkan perusahaan memperoleh kesuksesan dengan kualifikasi karyawan yang tidak memandang tinggi nilai-nilai material sebagai motivasi utamanya dalam bekerja (Karaman \& Aylan, 2012). Karyawan akan lebih fokus mengarahkan energinya untuk mencapai tujuan perusahaan, bersedia membantu kesulitan rekan kerja, memiliki keterikatan yang lebih baik dengan perusahaan, dan sepenuhnya menikmati peran dalam pekerjaanya (Andrew \& Sofian, 2014); (Christian, Garza, \& Slaughter, 2011); (Welch, 2011). Uraian tersebut menunjukkan bahwa organizational citizenship behavior merupakan salah satu elemen vital yang mempengaruhi keberhasilan perusahaan sehingga perlu dikaji faktor-faktor yang dapat mempengaruhi organizational citizenship behavior karyawan di perusahaan otomotif di Yogyakarta. Banyak sekali faktor-faktor yang mempengaruhi organizational citizenship behavior salah satunya adalah subjective well-being dan trust in the employer.

Hasil wawancara pada karyawan perusahaan otomotif menunjukkan bahwa karyawan-karyawan selama bekerja di perusahaan ini merasakan emosi postif dan emosi negatif seperti karyawan bangga dan senang bekerja di perusahaan karena merupakan perusahaan yang cukup besar. Karyawan percaya bahwa perusahaan ini dapat memberikan kepuasan hidup sesuai harapan masing-masing karyawan. Namun dalam prosesnya ketika karyawan telah bekerja selama bertahun-tahun juga muncul banyak permasalahan yang menimbulkan rasa kecewa karena perlakuan perusahaan yang dirasa kurang adil, saling menyalahkan karena adanya konflik antar karyawan, dan merasakan kondisi-kondisi kerja yang kurang diharapkan karyawan. Subjective wellbeing adalah sebuah konstruk tentang abstraksi kebahagiaan tertinggi individu yang melibatkan kepuasan hidup (Yurcu \& Akinci, 2017).

Konstruk ini awalnya dipopulerkan oleh Diener, Diener (2009) mendefinisikan subjective well-being sebagai suatu penilaian diri tentang pentingnya kehidupan individu berdasarkan reaksi emosionalnya dan evaluasi kognitif dari berbagai perspektif. Dalam konteks dunia kerja subjective well-being mencerminkan keadaan kesejahteraan karyawan dalam kehidupan kerjanya, dengan demikian karyawan dikatakan memiliki kesejahteraan apabila dirinya merasa puas dengan pekerjaanya, sering mengalami emosi positif seperti kegembiraan dan kebahagiaan, serta jarang mengalami emosi negatif seperti kekecewaan, kesedihan, dan kemarahan (Moore \& Diener, 2019). Kesejahteraan merupakan bagian penting dalam kehidupan kerja karyawan, karena berkaitan erat dengan berbagai konsekuensi positif seperti keterlibatan karyawan, organizational citizenship behavior, komitmen karyawan, dan tingginya kinerja karyawan (Stone \& Mackie, 2013); (Uçan \& Esen, 2015); (Yilman \& 
Arslan, 2013). Maka dari itu, penting bagi perusahaan untuk memastikan kesejahteraan karyawannya.

Menurut beberapa ahli karyawan dengan organizational citizenship behavior diiringi tingkat kebahagiaannya (Baranik \& Eby, 2016); (Dávila \& Finkelstein, 2015); (Yurcu, Çolakoğlu, \& Atay, 2015). Karyawan yang bahagia dalam kehidupan kerjanya cenderung memiliki organizational citizenship behavior yang lebih baik. Mengacu pada teori pertukaran sosial (Konovsky \& Pugh, 1994), ketika karyawan merasa puas dan bahagia dengan perlakuan perusahaan, karyawan akan memberi balasan melebihi dari apa yang diharapkan perusahaan terhadap dirinya dan mengabdikan dirinya dengan penuh dedikasi. Karyawan merasa dirinya memiliki ikatan emosional yang kuat dengan perusahaan, sehingga membuatnya bekerja tanpa mengejar penghargaan finansial ataupun kemajuan karirnya, melainkan untuk kepuasan pribadi dan kemajuan perusahaan (Diener, Scollon, \& Lucas, 2009); (Palihakkara \& Weerakkody, 2019); (Rego, Ribeiro, \& Cunha, 2010).

Trust in the employer adalah kepercayaan karyawan bahwa atasan akan melakukan tindakan yang bermakna dan tidak akan merugikannya secara sepihak (Yilmaz \& Atalay, 2009). Hasil wawancara menunjukkan bahwa karyawan-karyawan memiliki kepercayaan terhadap atasan dengan intensitas yang berbeda-beda. Karyawan menilai atasannya dari integritasnya, kompetensinya, konsistensinya, dan keterbukaannya terhadap karyawan. Ada pengalaman postif dan negatif yang dialami karyawan terhadap atasannya yang mempengaruhi tingkat kepercayaan karyawan terhadap atasannya. Kepercayaan ini terbentuk dari interaksi sehari-hari karyawan dengan atasan secara langsung yang menghasilkan pengalaman positif, seperti ketika atasan berkomitmen untuk menunjukkan kepeduliannya terhadap kesejahtraan karyawan, menerapkan kebijakan dengan adil dan jujur, serta memberi kepercayaan terhadap setiap karyawan tanpa memandang status jabatan (Searle \& Skinner, 2011); (Searle, Weibel, \& Hartog, 2011). Dalam penerapannya, trust in the employer berfungsi sebagai semacam perekat yang menyatukan hati dan emosi karyawan dengan atasannya.

Trust in the employer akan membentuk perilaku kooperatif yang dapat mengurangi kemungkinan konflik karyawan dengan atasan. Konflik ini umumnya disebabkan oleh kecemburuan karyawan terhadap rekan kerja karena adanya ketidakadilan dalam sebuah keputusan (Holland, Cooper, Pyman, \& Teicher, 2012). Karyawan cenderung lebih terbuka, jujur, dapat dipercaya, dan bertanggung jawab, ketika dirinya memiliki kepercayaan tinggi kepada atasannya. Karyawan akan lebih loyal dan sepenuhnya mendukung gagasan-gagasan yang dimiliki atasan. Dengan demikian karyawan akan termotivasi untuk memperdulikan dan bekerja lebih terhadap hal-hal yang dibutuhkan atasan untuk kemajuan perusahaan (Singh \& Srivastava, 2016); (Yildiz, 2019); (Yilmaz \& Altınkurt, 2012). Penelitian ini bertujuan untuk menguji pengaruh subjective well-being dan trust in the employer terhadap organizational citizenship behavior karyawan. 


\section{METODE}

Populasi dalam penelitian ini adalah karyawan tetap di salah satu perusahaan otomotif di Yogyakarta yang berjumlah 110 karyawan. Sampel penelitian ini adalah 70 karyawan dengan kharakteristik bekerja di perusahaan otomotif, masa kerja minimal satu tahun, berstatus sebagai karyawan tetap, tidak bekerja di bagian bengkel dan berjenis kelamin laki-laki dan perempuan. Pemilihan subjek penelitian dilakukan secara nonprobability dengan teknik purposive sampling karena berdasarkan karakteristik yang telah ditentukan oleh peneliti.

Penelitian ini menggunakan skala model Likert sebagai instrumen utama dalam memperoleh data empirik dari organizational citizenship behavior, subjective well-being, dan trust in the employer. Skala organizational citizenship behavior dan skala subjective well-being menggunakan skala yang telah disusun dalam penelitian sebelumnya dan skala trust in the employer disusun sendiri oleh peneliti. Skala diuji cobakan kepada 40 karyawan tetap perusahaan otomotif di Yogyakarta untuk mendapatkan validitas dan reliabilitas pengukuran.

Peneliti menggunakan skala organizational citizenship behavior dari Tentama dan Subardjo (2018) yang penyusunannya mengacu pada aspek organizational citizenship behavior dari Organ, Podsakoff, dan MacKenzie (2015), yaitu: counscientiousness, altruism, civic virtue, sportmanship, dan courtesy. Contoh aitem pada aspek counscientiousness adalah "Saya bersedia menjalankan tugas sesuai standar operasional yang ditetapkan" dan "Saya bersedia bekerja lembur ketika diperlukan". Contoh aitem pada aspek altruism adalah "Saya meluangkan waktu membantu rekan kerja dalam menyelesaikan pekerjaannya" dan "Saya bersedia menggantikan tugas rekan kerja yang berhalangan hadir". Contoh aitem pada aspek civic virtue adalah "Saya bekerjasama dalam kegiatan-kegiatan perusahaan" dan "Saya bekerja demi kepentingan perusahaan". Contoh aitem pada aspek sportmanship adalah "Saya memaklumi minimalnya fasilitasfasilitas yang diberikan perusahaan" dan "Saya membicarakan hal-hal yang positif mengenai perusahaan". Contoh aitem pada aspek courtesy adalah "Saya menyelesaikan tugas dengan sebaik baiknya agar tidak membebani rekan kerja" dan "Saya memberikan saran kepada rekan kerja yang melakukan kesalahan dalam bekerja". Berdasarkan analisis hasil uji coba diperoleh 15 aitem valid dan reliabel yang digunakan untuk penelitian dengan koefisien Cronbach's Alpha sebesar 0,863 dan indeks daya beda bergerak dari 0,255 sampai dengan 0,792 .

Skala subjective well-being menggunakan skala dari Saputra dan Tentama (2020), penyusunannya berdasarkan aspek subjective well-being dari Diener, Oishi, dan Lucas (2009), yaitu: kepuasan hidup dan afek positif-negatif. Contoh aitam dari aspek kepuasan hidup adalah "Dalam banyak hal hidup saya sesuai dengan cita-cita saya" dan "Sejauh ini saya telah mendapatkan hal-hal penting yang saya inginkan dalam hidup". Contoh aitem dari aspek afek positif-negatif adalah "Kagum", "Senang" dan "Kecewa", "Sedih". Berdasarkan analisis hasil uji coba diperoleh 33 aitem valid dan reliabel yang digunakan 
untuk penelitian dengan koefisien Cronbach's Alpha sebesar 0,920 dan indeks daya beda bergerak dari 0,256 sampai dengan 0,782.

Skala trust in the employer disusun dengan mengacu pada aspek trust in the employer menurut Lussier (2016), yaitu: integritas, kompetensi, konsistensi, loyalitas, dan keterbukaan. Contoh aitam dari aspek integritas adalah "Atasan saya lugas mengatakan apa yang dia maksud" dan "Atasan saya sangat menjaga kepercayaan yang diberikan". Aspek kompetensi direfleksikan oleh aitem "Saya rasa atasan saya berusaha sebaik mungkin dalam menjalankan tugasnya" dan "Atasan saya menggunakan prestasi kerja sebagai pembuktian diri, namun tetap rendah hati dalam bekerja". Contoh aitam dari aspek konsistensi adalah "Atasan saya tidak memberikan perlakuan istimewa pada pegawai tertentu" dan "Atasan saya bertanggung jawab dalam segala keputusan". Contoh aitam dari aspek loyalitas adalah "Atasan saya memberikan perlindungan terhadap karyawannya" dan "Atasan saya menjaga rahasia orang lain dengan baik". Contoh aitam dari aspek keterbukaan adalah "Sebagai karyawan saya merasa diberi kesempatan untuk mengenali pribadi atasan yang sesungguhnya" dan "Atasan saya mampu menerima pendapat orang lain". Berdasarkan hasil analisis uji coba diperoleh 28 aitem valid dan reliabel yang digunakan untuk penelitian dengan koefisien Cronbach's Alpha sebesar 0,958 dan indeks daya beda bergerak dari 0,389 sampai dengan 0,830.

Data empirik dari organizational citizenship behavior, subjective well-being, dan trust in the employer dianalisis menggunakan regresi linear berganda dengan bantuan SPSS V.21. Tujuan dari analisis regresi linear berganda adalah untuk menguji pengaruh antara subjective well-being dan trust in the employer dengan organizational citizenship behavior pada karyawan. Teknik regresi linear berganda merupakan salah satu teknik analisis statistik parametrik yang mengsyaratkan terpenuhinya uji asumsi yaitu uji normalitas, uji lineritas, dan uji multikolinearitas sebelum melakukan uji hipotesis.

\section{PAPARAN HASIL}

Uji prasarat dalam penelitian ini terdiri dari uji normalitas, lineritas, dan multikolinearitas. Hasil uji normalitas pada organizational citizenship behavior, subjective well-being, dan trust in the employer diperoleh skor residual KolmogorovSmirnov Z sebesar 0,102 dengan Asymp. Sig 0,067. Kaidah yang digunakan adalah $p>$ 0,05 , berdasarkan kaidah tersebut menunjukkan bahwa data organizational citizenship behavior, subjective well-being, dan trust in the employer terdistribusi dengan normal. Artinya tidak ada perbedaan antara sempel penelitian dengan populasi. Hasil analisis uji normalitas dapat dilihat pada Tabel 1.

Tabel 1. Hasil Analisis Uji Normalitas

\begin{tabular}{lccc}
\hline Variabel & Kolmogorov-Smirnov Z & Asymp. Sig. & Keterangan \\
\hline Unstandardized residual & 0,102 & 0,067 & Normal \\
\hline
\end{tabular}


Hasil uji linearitas subjective well-being dengan organizational citizenship behavior dan trust in the employer dengan organizational citizenship behavior diperoleh skor $F$ Linearity sebesar 45,987 dan 55,334 dengan taraf Sig 0,000. Kaidah yang digunakan adalah $p<0,05$, berdasarkan kaidah tersebut menunjukkan bahwa ada garis linear yang mengubungkan subjective well-being dengan organizational citizenship behavior dan trust in the employer dengan organizational citizenship behavior. Hasil uji linearitas dapat dilihat pada Tabel 2.

Tabel 2. Hasil Analisis Uji Linearitas

\begin{tabular}{lccc}
\hline \multicolumn{1}{c}{ Variabel } & F Linearity & Sig. & Keterangan \\
\hline $\begin{array}{l}\text { Subjective well-being dengan Organizational } \\
\text { Citizenship Behavior }\end{array}$ & 45,987 & 0,000 & Linear \\
$\begin{array}{l}\text { Trust in the employer dengan Organizational } \\
\text { Citizenship Behavior }\end{array}$ & 55,334 & 0,000 & Linear \\
\hline
\end{tabular}

Hasil uji multikolinearitas antara subjective well-being dan trust in the employer diperoleh skor tolerance dan VIF adalah sebesar 0,507 dan 1,973. Kaidah yang digunakan pada tolerance adalah > 0,1 dan pada VIF adalah < 10, berdasarkan kaidah tersebut dapat dikatakan bahwa semua variabel bebas tidak terjadi tumpang tindih atau kesamaan fungsi. Hasil uji multikolinearitas dapat dilihat pada Tabel 3. Ketiga uji asumsi yang telah dilakukan menunjukan bahwa semua persyaratan telah terpenuhi, sehingga dapat dilakukan uji hipotesis.

Tabel 3. Hasil Uji Multikolinearitas

\begin{tabular}{cccc}
\hline Variabel & Tolerance & VIF & Keterangan \\
\hline Subjective well-being & 0,507 & 1,973 & Tidak Terjadi Multikolinearitas \\
Trust in the employer & 0,507 & 1,973 & Tidak Terjadi Multikolinearitas \\
\hline
\end{tabular}

Uji hipotesis menggunakan uji regresi linear berganda. Hasil analisis secara parsial antara subjective well-being dengan organizational citizenship behavior dan trust in the employer dengan organizational citizenship behavior diperoleh skor Standardized Coefficients sebesar 0,328 dan 0,429 dengan taraf signifikansi 0,009 dan 0,001. Kaidah yang digunakan adalah $p<0,01$, berdasarkan kaidah tersebut menunjukkan bahwa ada pengaruh positif yang sangat signifikan antara subjective well-being dengan organizational citizenship behavior dan trust in the employer dengan organizational citizenship behavior. Hasil analisis korelasi partial dapat dilihat pada Tabel 4.

Tabel 4. Hasil Analisis Korelasi Partial

\begin{tabular}{lccc}
\hline \multicolumn{1}{c}{ Variabel } & $\begin{array}{c}\text { Standardized } \\
\text { Coefficients }\end{array}$ & Sig. & Keterangan \\
\hline $\begin{array}{l}\text { Subjective well-being dengan } \\
\text { Organizational Citizenship Behavior }\end{array}$ & 0,328 & 0,009 & Sangat Signifikan \\
$\begin{array}{l}\text { Trust in the employer dengan } \\
\text { Organizational Citizenship Behavior }\end{array}$ & 0,429 & 0,001 & Sangat Signifikan \\
\hline
\end{tabular}


Hasil analisis regresi linear berganda menunjukkan skor $F$ sebesar 32,143 dengan taraf signifikansi 0,000. Kaidah yang digunakan adalah $\mathrm{p}<0,01$, berdasarkan kaidah tersebut menunjukkan bahwa ada pengaruh positif yang sangat signifikan antara subjective well-being dan trust in the employer terhadap organizational citizenship behavior karyawan. Hasil analisis regresi linear berganda dapat dilihat pada Tabel 5.

Tabel 5. Hasil Analisis Regresi Linear Berganda

\begin{tabular}{lccccc}
\hline Variabel & $F$ & $R$ Square & Sig. & Keterangan \\
\hline $\begin{array}{l}\text { Subjective well-being dan Trust in the } \\
\text { employer terhadap Organizational }\end{array}$ & & & & \\
Citizenship Behavior & & & & \\
\hline
\end{tabular}

Secara simultan kontribusi subjective well-being dan trust in the employer terhadap organizational citizenship behavior sebesar 49\%. Besarnya kontribusi yang diberikan subjective well-being sebesar $20,66 \%$ dan besar kontribusi yang diberikan trust in the employer sebesar $28,31 \%$ sehingga dapat disimpulkan bahwa trust in the employer memberikan kontribusi yang lebih besar terhadap organizational citizenship behavior.

\section{PEMBAHASAN}

Hasil penelitian menunjukan bahwa subjective well-being dan trust in the employer trust in the employer secara simultan mempengaruhi organizational citizenship behavior, artinya karyawan akan menampilkan organizational citizenship behavior ketika karyawan merasa bahagia dan sejahtera dengan apa yang dirasakan pada dirinya dan karyawan sepenuhnya meyakini bahwa apa yang diperintahkan atasan adalah demi kebaikan dirinya. Meskipun masih jarang literatur sebelumnya yang mengkaji pengaruh subjective well-being terhadap organizational citizenship behavior, namun dari beberapa literatur yang ada, beberapa peneliti sebelumnya sependapat dengan temuan yang dihasilkan bahwa ada pengaruh positif antara subjective well-being dengan organizational citizenship behavior (Filsafati \& Ratnaningsih, 2016); (Purwito, Nurtjahjanti, \& Ariati, 2010). Karyawan merasa berkewajiban untuk terlibat dalam perilaku yang menguntungkan perusahaan atas dasar perlakuan positif yang telah dirinya dapatkan selama berada di perusahaan. Karyawan yang memiliki subjective well-being yang tinggi akan memberikan kontribusi bagi orang lain dan organisasi, perilakunya akan diperkuat karena saat melakukan kebaikan ia akan merasa lebih baik dan senang (Jex \& Britt, 2008). Tingginya emosi positif yang dirasakan di lingkungan kerja diasosiasikan berhubungan dengan kinerja yang lebih baik dan organizational citizenship behavior yang lebih tinggi (Diener, 2009).

Selain subjective well-being, adanya kepercayaan karyawan pada atasan berkaitan dengan sikap tidak ragu-ragu dari seorang karyawan (bawahan) kepada atasannya atas kebijakan yang dilakukan atasan tersebut. Karyawan yang memiliki kepercayaan yang tinggi terhadap atasannya akan cenderung menunjukkan perilaku konstruktif dalam bekerja. Karyawan mau mendengarkan semua arahan atasan, saling membantu dalam melaksanakan pekerjaan, dan menganggap atasan sebagai panutan bagi mereka dalam melaksanakan 
pekerjaan. Pada akhirnya kepercayaan terhadap atasan mendorong timbulnya organizational citizenship behavior di kalangan karyawan.

Pengaruh kepercayaan karyawan ini dapat direpresentasikan dalam berbagi cara, seperti membangun hubungan positif yang berkualitas dengan rekan kerja dan kesedian untuk melakukan tugas ekstra di luar pekerjaan rutinnya (Barzoki \& Rezaei, 2017); (Liu, Huang, Huang, \& Chen, 2013). Menurut teori pembelajaran sosial karyawan berperilaku sesuai dengan kondisi lingkungan kerjanya, dengan demikian ketika karyawan menilai atasannya dapat dipercaya, hal ini akan menginspirasi karyawan untuk berperilaku serupa atau bahkan membalasnya dengan menunjukkan organizational citizenship behavior (Hunter, Neubert, Perry, Witt, Penney, \& Weinberger, 2013). Terbukti adanya peningkatan keterlibatan kerja, komitmen karyawan, kinerja yang efektif, dan terbentuknya perilaku prososial ketika atasan memberikan efek positif pada bawahannya (Cem Gucel, 2012); (Dixon, 2013); (Mathur \& Negi, 2014).

Implikasi praktis hasil penelitian ini adalah perusahaan otomotif menyadari pentingnya menciptakan subjective well-being dan membangun kepercayaan karyawan pada atasannya dalam bekerja. Memperhatikan kebahagiaan dan kepuasan karyawan dalam bekerja merupakan salah satu cara mendorong karyawan untuk bersedia berpartisipasi ekstra dalam berbagai kegiatan yang memiliki kontribusi positif bagi perusahaan. Terlebih dengan adanya hubungan positif dan kepercayaan antara karyawan dan atasan, maka karyawan akan semakin termotivasi untuk bekerja ekstra (lebih) untuk memembalas semua kepercayaan yang telah diberikan perusahaan. Dengan demikian subjective well-being dan trust in the employer dapat bahan pertimbangan bagi perusahaan-perusahaan otomotif sebagai faktor psikologis yang harus diperhatikan dan ditumbuhkan pada karyawan dalam menjalankan aktivitas pekerjaannya karena akan berdampak pada meningkatkan organizational citizenship behavior karyawan. Implikasi teoritis penelitian ini yaitu dapat menjadi sumber referensi penelitian yang berkaitan dengan organizational citizenship behavior karyawan dan juga hasil penelitian ini mendukung dan relevan dengan hasil-hasil penelitian sebelumnya.

\section{SIMPULAN}

Subjective well-being dan trust in the employer memiliki kontribusi terhadap organizational citizenship behavior karyawan. Pentingnya perusahaan otomotif untuk berupaya memperhatikan dan menciptakan subjective well-being dan trust in the employer akan menumbuhkan perilaku bekerja ekstra pada karyawan yang sangat mendukung perusahaan dalam meningkatkan produktifitasnya. Perusahaan otomotif dapat mengutamakan faktor trust in the employer karena memberikan kontribusi yang lebih besar (dominan) dalam mempengaruhi organizational citizenship behavior. 


\section{DAFTAR PUSTAKA}

Andrew, O. C., \& Sofian, S. (2014). Engaging People who Drive Execution and Organizational Performance Engaging People who Drive. January 2011.

Bamel, U. K., Rangnekar, S., Stokes, P., \& Rastogi, R. (2013). Organizational climate and managerial effectiveness: An Indian perspective. International Journal of Organizational Analysis, 21(2), 198-218. https://doi.org/10.1108/IJOA-09-20110514

Baranik, L. E., \& Eby, L. (2016). Organizational citizenship behaviors and employee depressed mood, burnout, and satisfaction with health and life. Personnel Review, 45(4), 626-642. https://doi.org/https://doi.org/10.1108/PR-03-2014-0066

Barzoki, A. S., \& Rezaei, A. (2017). Relationship between perceived organisational support, organisational citizenship behaviour, organisational trust and turnover intentions: An empirical case study. International Journal of Productivity and Quality Management, 21(3), 273-299. https://doi.org/10.1504/IJPQM.2017.084456

Brockner, J., Flynn, F. J., Dolan, R. J., Ostfield, A., Pace, D., \& Ziskin, I. V. (2006). Commentary on "radical HRM innovation and competitive advantage: The Moneyball story." Human Resource Management, 45(1), 127-145. https://doi.org/10.1002/hrm

Cem Gucel, S. B. (2012). The effect of the servant leadership on organizational citizenship behavior: Case study of a university. International Journal of Social Sciences and Humanity Studies, 4(1), 107-116.

Christian, M. S., Garza, A. S., \& Slaughter, J. E. (2011). Work engagement: A quantitative review and test of its relations with task and contextual performance. Personnel Psychology, 64(1), 89-136. https://doi.org/10.1111/peps.12070

Jex, S. M., \& Britt, T. W. (2008). Organizational psychology. New York: John Willey \& Sons Inc.

Dávila, M. C., \& Finkelstein, M. A. (2015). Organizational citizenship behavior and wellbeing: Preliminary results. January 2013. https://doi.org/10.5923/j.ijap.20130303.03

Diener, E., Napa Scollon, C., \& Lucas, R. E. (2009). The evolving concept of subjective well-being: The multifaceted nature of happiness. In Social Indicators Research Series. https://doi.org/10.1007/978-90-481-2354-4

Diener, E. (2009). Subjective well-being. In Diener, E. (Eds). The Science of well-being. New York: Springer. https://doi.org/10.1007/978-90-481-2350-6

Diener, Ed, Oishi, S., \& Lucas, R. E. (2009). Subjective well-being: The science of happiness and life satisfaction. In Snyder, C. R., \& Lopez, S. J. (Eds.). In Oxford handbook of positive psychology. Oxford: Oxford University Press. https://doi.org/10.1093/oxfordhb/9780195187243.013.0017 
Dixon, D. (2013). Relationships among servant leadership, organizational citizenship behavior, and school climate in Alabama High Schools. (Doctoral Dissertation). Tuscaloosa: University of Alabama.

Filsafati, A., \& Ratnaningsih, I. Z. (2016). Hubungan antara subjective well-being dengan organizational citizenship behavior pada karyawan PT. Jateng Sinar Agung Sentosa Jawa Tengah \& DIY. Jurnal Empati, 5(4), 757-764.

Holland, P., Cooper, B. K., Pyman, A., \& Teicher, J. (2012). Trust in management: The role of employee voice arrangements and perceived managerial opposition to unions. Human Resource Management Journal, 22(4), 377-391. https://doi.org/10.1111/1748-8583.12002

Hunter, E. M., Neubert, M. J., Perry, S. J., Witt, L. A., Penney, L. M., \& Weinberger, E. (2013). Servant leaders inspire servant followers: Antecedents and outcomes for employees and the organization. Leadership Quarterly, 24(2), 316-331. https://doi.org/10.1016/j.leaqua.2012.12.001

Karaman, A., \& Aylan, S. (2012). Organizational citizenship [In Turkey Örgütsel vatandaşlik]. Kahramanmaraş Sütçü İmam Üniversitesi İktisadi ve İdari Bilimler Fakültesi Dergisi, 2(1), 35-48. Kahramanmaraş Sütçü İmam Üniversitesi İktisadi ve Idari Bilimler Fakültesi Dergisi, 2(1), 35-48. https://doi.org/10.14527/9786052410196.13

Kataria, A., Garg, P., \& Rastogi, R. (2012). Employee engagement and organizational effectiveness: The role of organizational citizenship behavior. International Journal of Business Insights \& Transformation, 6(1), 102-113.

Konovsky, M. A., \& Pugh, S. D. (1994). Citizenship behavior and social exchange. Academy of Management Journal. Academy of Management, 37(3), 656-669. https://doi.org/10.2307/256704

Liu, C. M., Huang, C. J., Huang, K. P., \& Chen, K. J. (2013). Psychological contract breach, organizational trust and organizational citizenship behavior of hotel industry in Taiwan. Pakistan Journal of Statistics, 29(5), 635-648.

Lussier, R. (2016). Human relation in organization: Applications and skill building. New York: McGraw-Hill.

Mathur, G., \& Negi, P. (2014). Servant leadership and organizational citizenship behaviour among employees of service sector. American International Journal of Research in Humanities, Arts and Social Sciences, 7(2), 191-196.

Moore, S., \& Diener, E. (2019). Types of subjective well-being and their associations with relationship outcomes. Journal of Positive Psychology and Wellbeing, 3(2), 112-118.

Ocampo, L., Acedillo, V., Bacunador, A. M., Balo, C. C., Joreen, Y., \& Tupa, N. S. (2018). A historical review of the development of organizational citizenship behavior (OCB) and its implications for the twenty-first century. Personnel Review, 47(4), 821-862. https://doi.org/10.1108/PR-04-2017-0136 
Organ, D. W., Podsakoff, P. M., \& MacKenzie, S. B. (2015). Organizational citizenship behavior: Its nature, antecedents, and consequences. California: Sage Publications.

Organ, D. (1988). Organizational citizenship behavior: The good soldier syndrome. New York: Lexington Books.

Palihakkara, N., \& Weerakkody, W. A. S. (2019). The impact of employee happiness on organizational citizenship behavior: A study of executive level employees in selected mobile telecommunication companies. Kelaniya Journal of Management, 8(1), 57. https://doi.org/10.4038/kjm.v8i1.7549.

Purwito, S., Nurtjahjanti, H., \& Ariat, J. (2010). Hubungan antara subjective well-being dan organizatonal citizenship behavior pada petugas customer service di Plasa Telkom Regional Division IV. Jurnal Psikologi Undip, 11(2), 12. https://doi.org/10.14710/jpu.11.2.12.

Rego, A., Ribeiro, N., \& Cunha, M. (2010). Perceptions of organizational virtuousness and happiness as predictors of organizational citizenship behaviors. Journal of Business Ethics, 93(2), 215-235. https://doi.org/10.1007/s10551-009-0197-7

Saputra, A., \& Tentama, F. (2020). Construction of the subjective well-being scale. International Journal of Scientific and Technology Research, 9(2), 38-42.

Searle, R., \& Skinner, D. (2011). Trust and human resource management. Cheltenham: Edward Elgar Publishing.

Searle, R., Weibel, A., \& Hartog, D. N. Den. (2011). Employee trust in organizational contexts. In Hodgkinson, G. P., \& Ford, J. K. (Eds.),. In International review of industrial and organizational psychology. Wiley-Blackwell.

Singh, U., \& Srivastava, K. B. L. (2016). Organizational trust and organizational citizenship behaviour. Global Business Review, 17(3), 594-609. https://doi.org/10.1177/0972150916630804

Stone, A. A., \& Mackie, C. E. (2013). Subjective well-being: Measuring happiness, suffering, and other dimensions of experience. Washington: National Academies Press.

Tentama, F., \& Subardjo. (2018). Pengujian validitas dan reliabilitas konstruk pada organizational citizenship behavior. Humanitas: Jurnal Psikologi Indonesia, 15(1), 62. https://doi.org/10.26555/humanitas.v15i1.5282

Uçan, A. A., \& Esen, B. B. (2015). Investigating subjective well-being of adolescents according to risk taking variable related to social position [In Turkey Ergenlerin öznel iyi oluşlarının toplumsal konum ile ilgili risk alma değişkenine göre incelenmesi]. Journal of the Faculty of Education Mersin University, 11(2), 288299. https://doi.org/10.5350/dajpn2011240106

Welch, M. (2011). The evolution of the employee engagement concept: Communication implications. Corporate Communications: An International Journal, 16(4), 328- 
346. https://doi.org/10.1108/13563281111186968

Yildiz, H. (2019). The interactive effect of positive psychological capital and organizational trust on organizational citizenship behavior. SAGE Open, 9(3), 115. https://doi.org/10.1177/2158244019862661

Yilman, H., \& Arslan, C. (2013). Subjective well-being: Positive and negative affect in Turkish students. The Online Journal of Journal of Counseling and Education, 2(2), 1-8.

Yilmaz, A., \& Atalay, C. G. (2009). A theoretical analysis on the concept of trust in organizational life. European Journal of Social Sciences, 8(2), 341-352.

Y1lmaz, K., \& Altınkurt, Y. (2012). The relationship between organizational justice, organizational trust and organizational citizenship behaviors in secondary schools in Turkey. In Duyer, I., \& Normore, A. (Eds,). Discretionary behavior and performance in educational organizations: The missing link in educational leadership and management. Emerald. https://doi.org/10.14812/10

Yurcu, G., \& Akinci, Z. (2017). Influence of organizational citizenship behavior on hotel employees' job satisfaction and subjective well-being. Advances in Hospitality and Tourism Research, 5(1), 57-83.

Yurcu, G., Çolakoğlu, Ü., \& Atay, H. (2015). The effect of organizational citizenship behavior on subjective well-being. International Journal of Business and Social Science, 68(1), 120-130. 